\title{
Applied Physiology and the Hemodynamic Management of Septic Shock Utilizing the Physiologic Optimization Program
}

\author{
William McGee and Patrick Mailloux \\ Baystate Medical Center, Tufts University School of Medicine \\ United States
}

\section{Introduction}

Volume management is an important aspect of caring for patients with sepsis. Multiple factors contribute to the challenge of resuscitating septic patients, including volume depletion, a decrease in vascular tone and myocardial depression. Goal directed therapy incorporates the use of physiologic targets to guide fluid resuscitation in this population, taking into account the changes in physiology of a patient with sepsis. Further, evolving technology and knowledge is allowing for a better understanding of endpoints when managing fluids in this critically ill patient group.

Patient's presenting with hypo-perfusion secondary to septic shock benefit from early, aggressive resuscitation in a protocolized manner (Rivers, 2001). The goals of initial resuscitation, to be achieved within 6 hours of presentation, include a central venous pressure of $8-12 \mathrm{mmHg}$, mean arterial pressure (MAP) of $\geq 65 \mathrm{mmHg}$, urine output $\geq 0.5$ $\mathrm{mL} / \mathrm{kg} / \mathrm{hr}$ and a central venous $\left(\mathrm{ScvO}_{2}\right)$ or mixed venous oxygen saturation $\geq 70 \%$ or $65 \%$, respectively (Rivers 2001, Dellinger, 2008). This concept is known as early goal directed therapy (EGDT) (Rivers, 2001).

\subsection{Oxygen delivery}

The ultimate goal of early resuscitation is to achieve adequate oxygen delivery so the balance between supply and demand to vital organs is maintained. A critical level of oxygen delivery $\left(\mathrm{DO}_{2}\right)$ exists for septic patients and increasing the $\mathrm{DO}_{2}$ above that level does not further increase oxygen consumption. (Ronco, 1993; Shibutani, 1983;, Danek, 1980; Nelson, 1987,1988 ) When below critical $\mathrm{DO}_{2}$, oxygen utilization is dependent upon $\mathrm{DO}_{2}$ (Figure 1), compensation via increased oxygen extraction is no longer sufficient, oxygen debt develops and anaerobic metabolism ensues. (Pieracci, 2011) One accepted method to measure whether $\mathrm{DO}_{2}$ is above this threshold involves determining the oxygen saturation of venous blood returning to the heart (McGee \& Jodka, 2002; Krafft, 1993). $\mathrm{ScvO}_{2}$ as a proxy for $\mathrm{SVO}_{2}$ is reasonable (Lee, 1972; Reinhart, 2004; Ladakis, 2001) and reflects the oxygen saturation of SVC blood. As the saturation of venous blood (Figure 2) declines, oxygen consumption is increasing for a constant value of oxygen delivery, or oxygen delivery itself may be declining. In either circumstance assessment of $\mathrm{ScVO}_{2}$ represents the balance between 
delivery and consumption simultaneously and can be measured continuously alerting the clinician to reassess the components of both delivery and consumption. Critical imbalances often require acute intervention to assure survival and prevent organ dysfunction. Lower values are the result of increased oxygen extraction at the tissue level typically due to decreased oxygen delivery $\left(\mathrm{DO}_{2}\right)$ and values $<70 \%$ suggest tissue hypoperfusion. If the $\mathrm{ScVO}_{2}$ drops below $50 \%$ there is an increased risk of developing anaerobic metabolism and lactic acidosis. (Simmons, 1978) Low or declining $\mathrm{ScVO}_{2}$ indicates further manipulation of $\mathrm{DO}_{2}$ or less commonly $\mathrm{VO}_{2}$ may be necessary to assure adequate cellular oxygenation. (Rivers, 2001; Lee, 1972; Kasnitz, 1976; Reinhart, 1989)

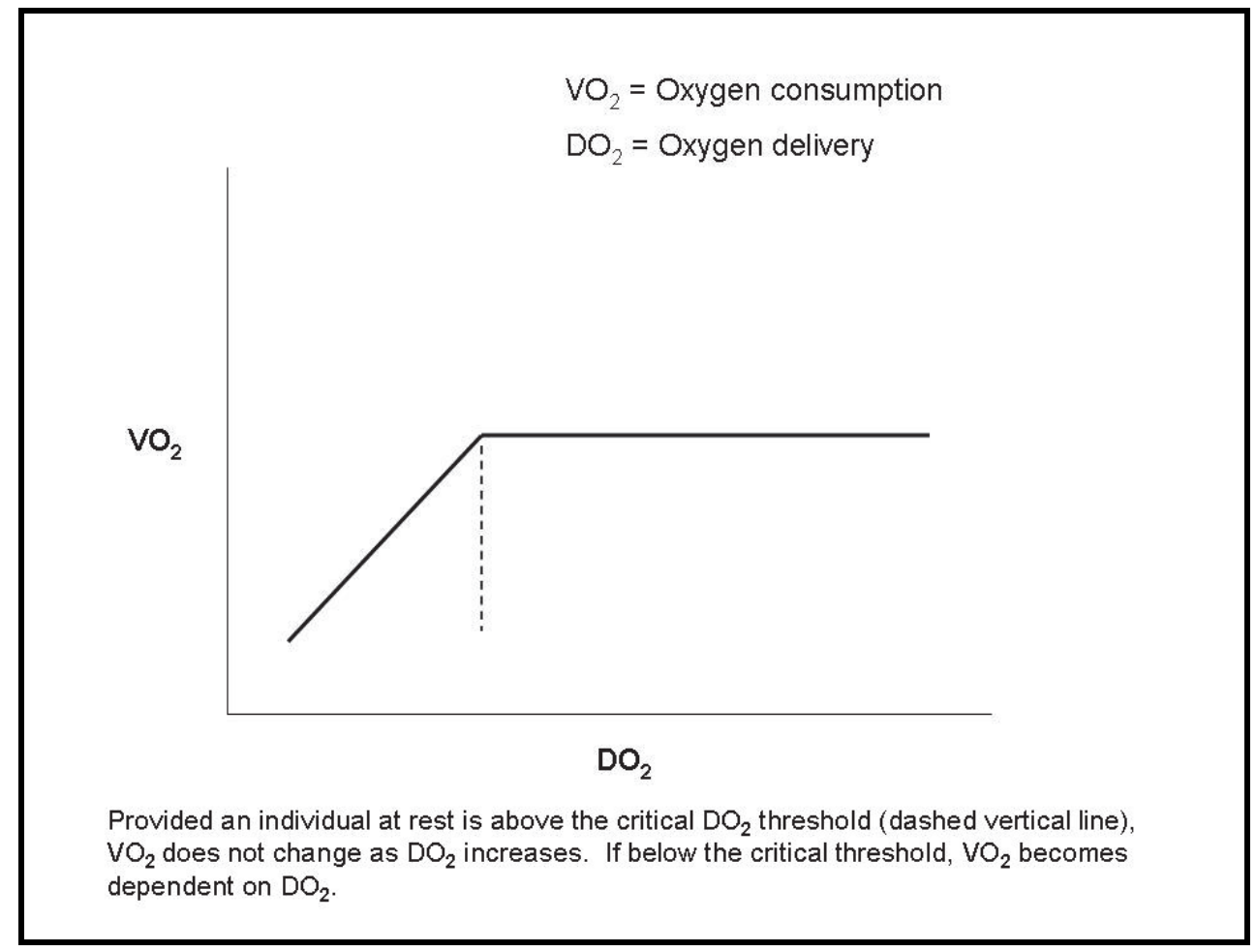

Fig. 1.

\subsection{Therapeutic targets}

Multiple studies demonstrated the survivors of high stress situations induced by surgery, sepsis, trauma or cardiac insults achieved a higher cardiac index, oxygen delivery (DO2) and oxygen consumption (VO2) as compared to non-survivors (Heyland, 1996; Shoemaker, 1993, Bishop, 1993; Shoemaker, 1993; Edwards, 1989; Gilbert, 1986; Shoemaker, 1993; Creamer, 1990; Hankein, 1991; Hayes, 1993; Kankein, 1987; Cryer, 1989). As a result of these findings, efforts were made to target these variables in an effort to improve outcomes of the critically ill. The first randomized, controlled trial (Shoemaker, 1988) implemented protocols to generate supraphysiologic values as therapeutic goals in high risk surgical patients. 
Patients with oxygen transport maximized by a PA catheter protocol had a lower mortality, reduced duration of mechanical ventilation and ICU stay. Study limitations in baseline characteristics of the various groups along with an unblinded design raise the question of bias versus an actual treatment impact (Shoemaker, 1988; Heyland, 1996).

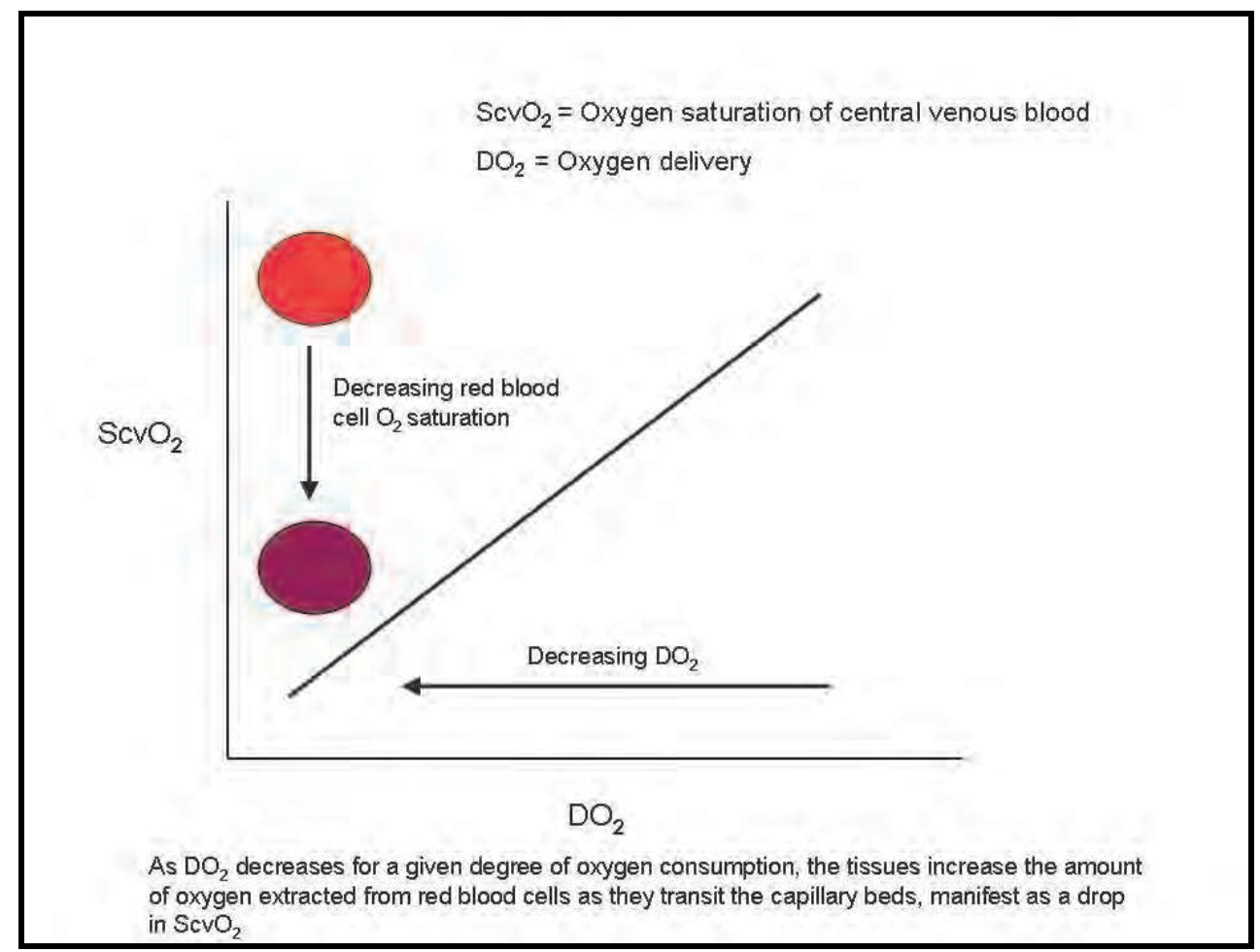

Fig. 2.

Hayes et al (Hayes, 1994) randomly assigned patients failing to reach established therapeutic goals following volume resuscitation alone to continue with standard care or receive dobutamine to increase cardiac index, oxygen delivery and oxygen consumption. The treatment group had a higher mortality, suggesting efforts to achieve supranormal physiologic targets may result in more risk than benefit. In addition, Gattinoni et al (Gattinoni, 1995) failed to demonstrate a favorable impact on morbidity or mortality when targeting hemodynamic therapy to achieve supranormal values for cardiac index or normal values for mixed venous oxygen saturation.

In 2001, Rivers et al (Rivers, 2001) published the results of a randomized trial of EGDT in the treatment of patients with severe sepsis and septic shock. By instituting a multi-faceted protocol targeted to increase oxygen delivery they were able to demonstrate significant benefits to outcome in this patient population. The main components of this approach included continuous monitoring of central venous oxygen saturation $\left(\mathrm{ScvO}_{2}\right)$, treatment in a dedicated area of the emergency department for the first six hours and fluid boluses to achieve a central venous pressure (CVP) of 8 to $12 \mathrm{mmHg}$. If the MAP remained $<65 \mathrm{mmHg}$ 
following fluid resuscitation to a CVP of $8-12 \mathrm{mmHg}$, vasopressor therapy began, red blood cells were transfused to achieve a hematocrit of at least $30 \%$ if the $\mathrm{ScvO}_{2}$ was less than $70 \%$ and dobutamine administration titrated to achieve an $\mathrm{ScvO}_{2}$ of at least $70 \%$ despite the other interventions. (Rivers, 2001) The intervention group was more likely to achieve the $\mathrm{ScvO}_{2}, \mathrm{CVP}, \mathrm{MAP}$ and urine output goals along with an improvement in mortality. $46.5 \%$ in those receiving standard therapy died compared to $30.5 \%$ in the EGDT cohort $(p=0.009)$. The EGDT group also received significantly more fluid $(4981 \mathrm{~mL}$ vs. $3499 \mathrm{~mL})$, red blood cells (64.1\% transfused vs. $18.5 \%)$, and inotropic support (13.7\% vs. $0.8 \%)$ during the first 6 hours. The difference in fluid balance did not persist at 72 hours $(13,443 \mathrm{~mL}$ in EGDT vs. 13,358 in standard therapy) emphasizing the importance of rapid volume optimization for septic shock. (Rivers, 2001) This study demonstrated for the first time the importance of an aggressive, early, protocolized, goal directed treatment regimen in caring for patients with severe sepsis and septic shock. This protocol has been adopted in multiple guidelines as the standard of care for treating septic patients (Dellinger, 2008). Table 1 summarizes the findings of the above trials.

\begin{tabular}{|c|l|l|}
\hline Study & \multicolumn{1}{|c|}{ Intervention } & \multicolumn{1}{c|}{ Results } \\
\hline Shoemaker, 1988 & $\begin{array}{l}\text { Supraphysiologic values as } \\
\text { therapeutic goals in high risk surgical } \\
\text { patients }\end{array}$ & $\begin{array}{l}\text { Oxygen transport } \\
\text { maximized by a PA } \\
\text { catheter protocol lead to } \\
\text { lower mortality, reduced } \\
\text { duration of mechanical } \\
\text { ventilation and shorter ICU } \\
\text { stay }\end{array}$ \\
\hline Hayes, 1994 & $\begin{array}{l}\text { Dobutamine to increase cardiac } \\
\text { index, oxygen delivery and oxygen } \\
\text { consumption }\end{array}$ & $\begin{array}{l}\text { Higher mortality in } \\
\text { patients treated with } \\
\text { dobutamine compared to } \\
\text { standard care }\end{array}$ \\
\hline Gattinoni, 1995 & $\begin{array}{l}\text { Achieving supranormal values for } \\
\text { cardiac index or normal values for } \\
\text { mixed venous oxygen saturation }\end{array}$ & $\begin{array}{l}\text { No improvement on } \\
\text { morbidity or mortality }\end{array}$ \\
\hline Rivers, 2001 & $\begin{array}{l}\text { Early goal directed therapy with CVP } \\
\text { of } 8-12 \text { mmHg, vasopressors if } \mathrm{MAP} \\
<65 \text { mmHg following fluid } \\
\text { resuscitation, ScvO } \geq 70 \%, \\
\text { dobutamine and red blood cells to } \\
\text { keep hematocrit at least 30\% if ScvO } 2 \\
<70 \%\end{array}$ & $\begin{array}{l}\text { Improved mortality with } \\
\text { intervention compared to } \\
\text { standard care. More fluid, } \\
\text { red blood cells and } \\
\text { inotropic support during } \\
\text { first 6 hours in intervention } \\
\text { group. }\end{array}$ \\
\hline
\end{tabular}

Table 1. Summary of Studies on Goal Directed Therapy

\subsection{Physiological derangements}

Aggressive fluid resuscitation is a mainstay of therapy for septic patients as this population tends to be severely hypovolemic related to multiple mechanisms, venodilation from altered vascular tone leads to pooling of blood in the capacitance vessels. (McGee \& Jodka. 2002; Kumar, 2009, Teule 1984) Septic patients also have extravasation of fluid into the interstitium related to increased permeability of the capillary endothelium (Rivers 2008; 
Pieracci 2011). These phenomena result in decreased preload, cardiac output and inadequate oxygen delivery. It remains essential to restore volume status and improve cardiac performance. Additionally, the body's inflammatory response is further modulated by cellular hypoxia brought about by the decline in bulk oxygen delivery (Rivers, 2007) may compound the physiologic derangement.

Concurrent with the needs to restore adequate preload and circulating blood volume, septic patients often demonstrate myocardial depression. This dysfunction is related to the presence of myocardial depressant factors early in the septic process, not decreased myocardial perfusion, and include cytokines, tumor necrosis factor alpha (TNF- $\alpha$ ) and interleukin one beta (IL-1 $\beta$ ) acting synergistically. (Court, 2002; Pathan, 2002) Additionally, nitric oxide generation, interstitial myocarditis, calcium trafficking, endothelin receptor antagonists and apoptosis likely all contribute to the ongoing process of myocardial depression. (Fernandes, 2008). This is manifest as a low cardiac output concurrent with a decrease in ejection fraction and oxygen delivery despite adequate filling pressures. Ventricular interdependence and impairment of left ventricular filling may be an important concern especially with concomitant ARDS and RV dysfunction/dilatation. (Michard, 2010; von Ballmoos, 2010)

The use of echocardiogram plays an important role in quantifying the degree of dysfunction as it is used to assess biventricular contractility and identifies hemodynamically unstable patients who will benefit from either inotropic support or further volume expansion (Griffee, 2010; Beaulieu, 2007). Dobutamine is a typical first line inotropic agent when myocardial depression of sepsis is confirmed and the goal is to establish adequate oxygen delivery or tissue perfusion as measured by $\mathrm{ScvO}_{2}$. No benefit is seen using inotropes to create a supra-physiologic state though studies achieving this did not have echocardiogram data to determine what proportion of subjects had impaired contractility (Hayes, 1994; Gattinoni, 1995). Sepsis induced myocardial depression usually resolves completely over the course of the illness for survivors. (Griffee, 2010; Parker, 1984).

\subsection{Role of red blood cells}

Controversy exists as to the ideal hemoglobin concentration for septic patients undergoing EGDT as the risks of transfusion often outweigh the benefits. (Hebert, 1999; Marik, 2008; Fuller, 2010) The goal of transfusion of red blood cells is to improve $\mathrm{DO}_{2}$. There is no impact on the sublingual microcirculation as detected by an orthogonal polarization spectral device in septic patients receiving a red blood cell transfusion (Sakr, 2007). Further, transfusing anemic, septic patients does not improve either regional or global oxygen utilization as determined by either the Fick equation or indirect calorimetry and may increase pulmonary vascular resistance, further hindering right ventricular function. (Fernandes, 2001; Bone, 1993) At this time unless there is active myocardial ischemia, it is difficult to define exact triggers for transfusion of red blood cells in septic patients undergoing active resuscitation. (Pieracci, 2011)

\subsection{Avoiding volume overload}

An aggressive, early intervention targeted at improving hemodynamic performance in septic patients improves outcomes and is now recognized as the standard of care. The trigger to transfuse red blood cells during the early resuscitation of septic patients remains controversial and is a major criticism of EGDT, especially given the known complications of 
providing transfusions to critically ill patients. Critical care practitioners need to recognize both the importance of implementing EGDT and avoiding the deleterious effects of fluid overload. When septic patients have a more positive fluid balance both early in the resuscitation process and cumulatively over 4 days there is an associated increased risk of mortality (Boyd, 2011). The importance of carefully managing fluids is further illustrated in patients with acute lung injury or ARDS as those with a lower cumulative fluid balance demonstrate improved outcomes. (Murphy, 2009; the NHLBI ARDSNet, 2006) When complicated by acute kidney injury, fluid overload further impacts mortality in critically ill patients (Payen, 2008; Bouchard, 2009)

\section{Applied physiology for the management of severe sepsis/septic shock}

The foundation of all resuscitation strategies for severe sepsis and septic shock is volume therapy. Early goal directed therapy is complicated by the requirement for central venous access which is not always available especially during the initial patient evaluation, and the use of a CVP target which has been called in to question as a meaningful measure of preload responsiveness. (Michard, 2002; Marik, 2008;Osman, 2007) Additionally although rapid resuscitation is important excess volume that does not improve cardiac performance is potentially contributing to complications; excess length of stay (Wiedemann, 2006) and mortality (Murphy, 2009). Generally as the goal of any volume therapy in the critically ill is to improve cardiac performance, we propose physiology based hemodynamic therapy for the severely septic patient that considers the pathophysiology already described.

\subsection{Physiologic optimization program for sepsis resuscitation, dynamic variables of volume responsiveness}

Utilizing dynamic variables of volume responsiveness to guide resuscitation allows precise titration of preload with clear endpoints for fluid resuscitation to minimize the risk of inappropriate fluid overload. Dynamic variables of volume responsiveness, stroke volume variation (SVV) and pulse pressure variations (PPV) exploit the physiology of the heart/lung interaction during positive pressure ventilation that relates the variation of stroke volume or pulse pressure to the degree of volume responsiveness. The respirophasic change in blood pressure (commonly observed in the arterial pressure tracing) of hypovolemic patients is a well known example. (McGee, 2009) (Figure 3).

The available devices quantify the variability and display the variation as a primary output. This variation is highly correlated with the degree of volume responsiveness, i.e., the greater the variation, the greater the expected response to a volume challenge. (Figure 4).

This approach is available only for patients with controlled positive pressure ventilation without a significant dysrhythmia as the utility of SVV or PPV to assess volume responsiveness is not valid beyond these conditions. The use of the dynamic variables SVV and PPV, especially during early resuscitation prior to intubation is generally not possible. Resuscitation of these patients, however, is straight forward and relies on titration of volume against cardiac performance measured by SV and CO. This approach provides assurance that preload optimization has occurred prior to implementation of pharmacotherapy. Our preference is to use the indexed values in an attempt to normalize targets across variability in body surface area. This may be problematic in the super obese (McGee, 2006). (Figure 5). 


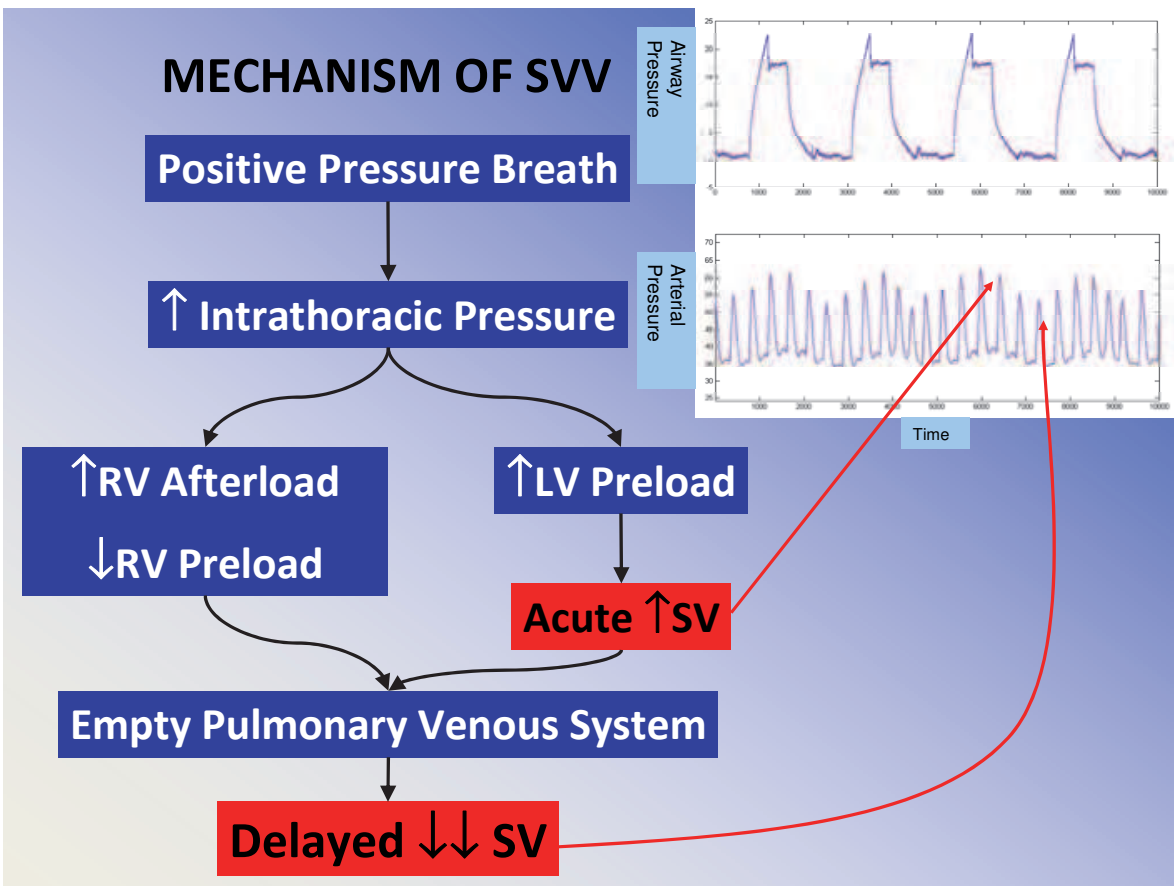

Fig. 3. The phasic change in blood pressure and its timing to the ventilatory cycle is illustrated with four positive pressure breaths and the simultaneously displayed arterial waveform directly below it. Blood pressure goes up during the inspiratory phase of mechanical ventilation and decreases during expiration. The swings in blood pressure (pulse pressure variation, PPV) are generated by the change in stroke volume SV (stroke volume variation, SVV) effected by positive pressure ventilation. The variability is respirophasic as this figure illustrates. The impact on right (RV) and left ventricular (LV) pre and afterload induced by positive pressure ventilation is shown.

In those clinical settings where SVV or PPV does not predict volume responsiveness how can this be determined? As long as stroke volume can be measured this question can be answered. This represents a huge advantage of the technologies that allow measurement of stroke volume and cardiac output, FloTrac/Vigileo, PICCO, and LiDCO, over those that simply provide pulse pressure variation, which is now readily available on bedside monitors that display an arterial waveform (IntelliVue MP90, 2006). This physiology also explains why this literature has been primarily developed in the operating room where ideal conditions often exist for the measurement and application of dynamic parameters, namely controlled mechanical ventilation with a large enough tidal volume to induce a significant change in pleural pressure to impact venous return. A threshold value for tidal volume of 8 cc per kilogram ideal body weight has been determined in several studies that evaluated the tidal volume necessary to meaningfully impact venous return. (Feissel, 2001; Tavernier, 1998; Michard, 2000; Perel, 1987) Across a heterogeneous population, this may be true, although there will be specific examples depending on the patient's lung compliance and intravascular volume status where it may not be. 


\section{Magnitude of SVV is Related to LV Preload}

\section{Change in preload related to positive pressure ventilation}



Fig. 4. Legend: A and B represent different locations on the Starling Curve. The change in preload induced by the ventilator is identical. The impact on SV is not. The change in SV induced by one positive pressure breath is proportional to SVV. SVV determines the magnitude of preload dependency. Patients with higher SVV are more volume responsive (A - preload dependent) functioning on the steeper portion of the Frank Starling curve. SVV decreases as preload dependent LV function is optimized (B - preload independent). In these patients (B) volume can be safely removed as cardiac performance is not influenced by changes in preload. SVV/SVI pairs allow individual discrimination of a patient's Starling curve that can determine when volume is required to improve cardiac performance and conversely when volume can be safely removed. SV (stroke volume) SVV (stroke volume variation)

At lower tidal volumes, false negatives where stroke volume variation is low, and the patient is still significantly volume responsive occur. Extreme examples of this were encountered during the H1N1 flu epidemic in the fall of 2009, where many patients were being oscillated at very high frequencies but with minimal tidal volume and hence pleural pressure change. These patients could be significantly volume responsive with essentially no stroke volume or pulse pressure variation because of the very small change in pleural pressure induced with this strategy of ventilation. Similarly, patients being ventilated using a low tidal volume strategy for ALI/ARDS may manifest a similar phenomenon. In those patients, teasing out volume responsiveness utilizing physiology is fairly simple. Listed below are three possible strategies to ascertain volume responsiveness when SVV is unable to provide direction: (DeBacker, 2005) 


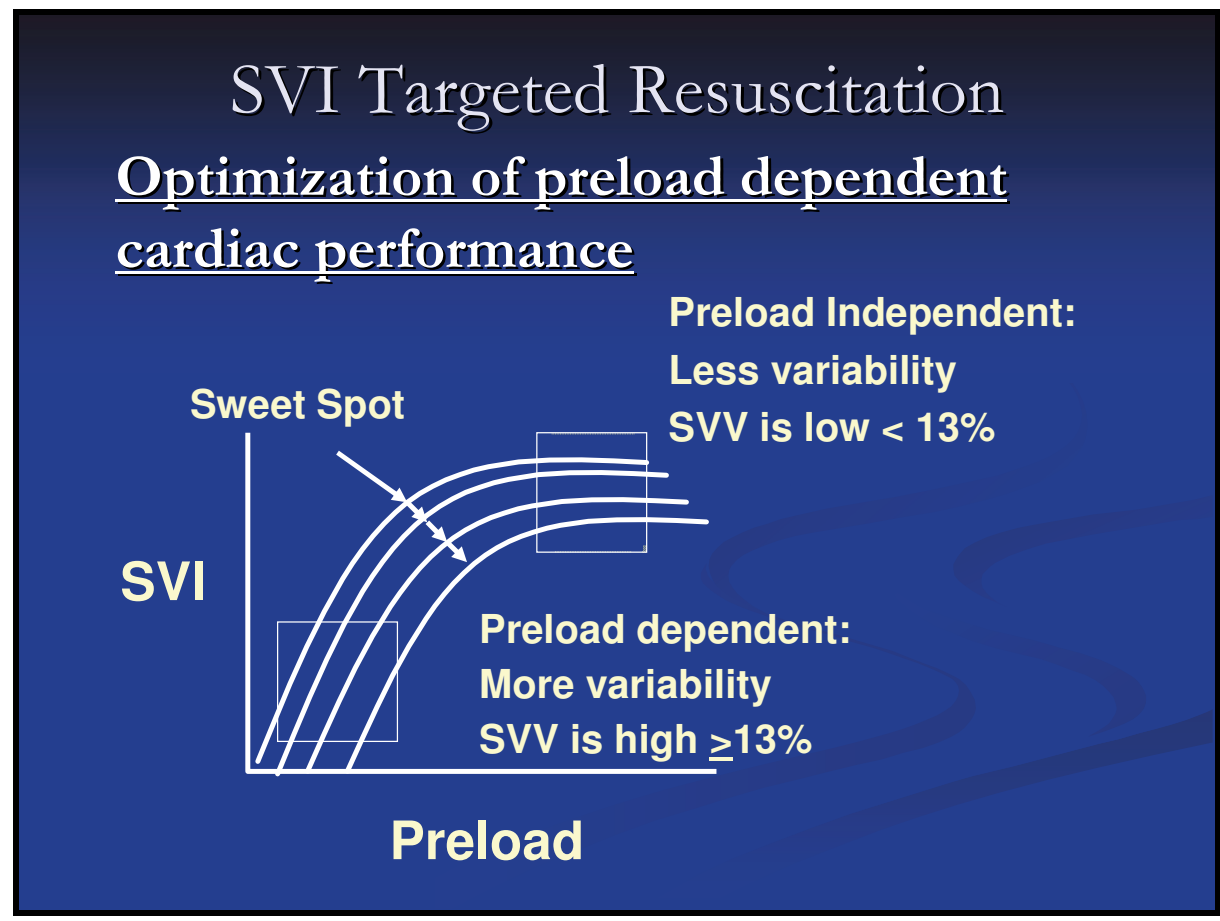

Fig. 5. The goal of volume therapy during resuscitation is to optimize the use of preload augmentation of cardiac function. Stroke volume variation is a very useful parameter to allow rapid safe resuscitation. When this parameter is not useful (dysrhythmia, small tidal volume, spontaneous breathing), simply targeting the maximum stroke volume index (SVI), is another means to guide volume therapy. Independent of which Frank-Starling Curve the patient is on ,the goal of volume therapy is always the same during resuscitation; to obtain the most benefit from the preload dependent portion of the Frank-Starling Curve. These techniques have the additional benefit of more precisely targeting the "sweet spot" of the Frank-Starling Curve without excessive volume overload.

\subsection{Stroke volume index targeted resuscitation: Obtaining the sweet spot on the Frank-Starling curve (figure 5)}

1. Recruitable stroke volume:

Increase the tidal volume to at least $8-10 \mathrm{cc} / \mathrm{kg}$ and look for the change in SVV. For volume responsive patients, once beyond a threshold value for tidal volume, volume responsiveness becomes apparent as the SVV will increase to greater than $10-13 \%$, a reliable cutoff above which patients are generally volume responsive. The time responsiveness of these technologies is fairly rapid and tidal volume needs to be increased for only a short period of time, typically less than 5 minutes. Physician presence at the bedside during this maneuver is important to:

a. View the change; and

b. Assure that the pressure encountered with the ventilation change is not harmful to the patients. If this change in tidal volume results in SVV becoming greater than $10-13 \%$, a 
fluid bolus is then given after the patient has been returned to the initial ventilator settings.

Two additional strategies are also useful for non-ventilated patients or those with significant dysrhythmias.

2. The passive leg raising maneuver (PLR) ((Cavallaro, 2010, Monnet, 2006) (Figure 6.)

\section{Passive Leg Raising}

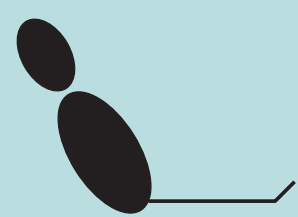

Baseline

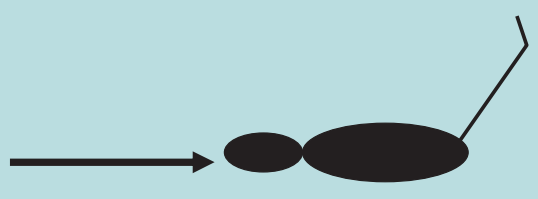

PLR

Data recorded after

120 s

Patients who respond to the PLR maneuver will also respond to a fluid bolus. Response described in text.

Fig. 6.

The patient is placed flat and the legs are elevated to 45 degrees and the change in stroke volume and cardiac output is recorded. Those patients that have a positive response usually defined as greater than $12-15 \%$ increase in cardiac output are then given a fluid challenge, typically $250-500 \mathrm{cc}$ of colloid or crystalloid. This can be done numerous times until the indicator of volume responsiveness disappears or an adequate stroke volume/cardiac output is reached. Although the change in SV using aortic flow is fully apparent within 30 seconds, the increase in venous return that this maneuver induces in cardiac performance requires the legs be elevated for roughly 120 seconds to allow for the time constraints of the pulse contour technology. (Teboul, 2009; Biais, 2009) In numerous studies, this has been shown to be essentially a perfect test as a measure of volume responsiveness as long as the improvement in stroke volume/cardiac output is the cardiac performance parameter of interest. (Cavallaro, 2010) Simply looking at the change in blood pressure is not helpful. (Monnet, 2006) This technique works well especially in those patients who are either spontaneously breathing or have a significant dysrhythmia. This reversible volume challenge is most useful in patients with acute lung injury or ARDS or those with either acute or chronic renal failure, where giving a volume challenge that does not result in 
improvement in cardiac performance may in fact be detrimental to the patient. (Cavallaro, 2010; McGee, 2009)

3. Volume challenges: As long as there is a cardiac performance measure, stroke volume or cardiac output, simply giving a fluid bolus and assessing its impact on cardiac performance is a reasonable way to assess volume responsiveness for patients where we suspect that additional volume will not be injurious, i.e. clear lungs and without renal failure. If cardiac performance does not improve, volume is not the correct therapy (Figure 5).

It is important to recognize when the patient is on the flat part of the Frank-Starling Curve and not responding to volume. Excess volume therapy has been associated with increased length of stay, increased time on mechanical ventilation, and mortality. (Boyd, 2011; Murphy, 2009; the NHLBI ARDSNet, 2006; Payen, 2008; Bouchard, 2009; Maitland, 2011) The major impact of using these technologies well is that we now have the ability for precise titration of volume management in the majority of critically ill patients. The simple premise underlying volume therapy in the ICU or OR is to affect a change in cardiac performance. This simply is not possible without a cardiac performance measure.

\subsection{Physiologic optimization program (figure 7)}

Figure 7 illustrates the use of dynamic parameters of volume responsiveness for the hemodynamic management of patients with severe sepsis or septic shock. Volume responsive patients SVV $\geq 13 \%$ receive volume therapy titrated against both SVV and SVI. For non-volume responsive patients, the physiology is interrogated at the level of cardiac performance on a beat to beat basis. Ultimately and with this approach rapidly a majority of patients will develop a SVI $\geq$ normal (pathway 1). This represents resuscitated septic shock and these patients may be safely placed on a vasopressor, knowing that volume resuscitation has been accomplished. Precise volume titration can be maintained but once SVI is supraphysiologic (pathway 3) volume therapy is stopped and diuretics might be warranted for that population who go on to develop ALI/ARDS typically after the initial resuscitation phase. Approaches to the patient in pathway 2 will be discussed in the text (McGee, 2009).

\subsection{Assessment of oxygen delivery}

Non-volume responsive patients (SVV $<13 \%$ ) with low SVI or CO are a particularly challenging population. $\mathrm{DO}_{2}$ adequacy must be determined on an individual basis. This will also apply to some patients with normal SVI or CO. $\mathrm{O}_{2}$ extraction is particularly useful in this regard facilitating determination of the adequacy of bulk oxygen transport. When extraction is low or normal $(<33 \%)$ augmentation of $\mathrm{DO}_{2}$ has not been shown to be helpful. (Gattinoni, 1995, Hayes 1994) Alternatively, high extraction (>40\%) usually precipitates some attempt at $\mathrm{DO}_{2}$ optimization, although this approach has not been rigorously evaluated, it remains the basis of all resuscitation strategies. It is clear that as $\mathrm{O}_{2}$ extraction increases, physiologic reserve is compromised, lactic acidosis ensues, and mortality results. Using $\mathrm{O}_{2}$ extraction as an endpoint further refines hemodynamic care of this severely ill group of patients and is the physiologic foundation of early goal directed therapy. 




Fig. 7.

\section{Physiologic Optimization Program SVV, SVI, \& ScVO2}

\section{Volume Responsive: SVV>13\%}

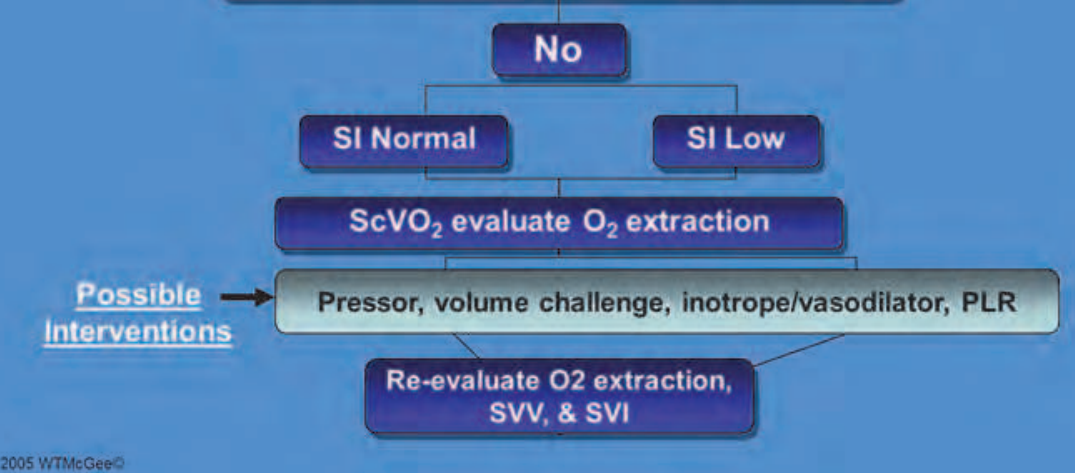

Fig. 8 . 
For those patients with extraction greater than normal but not excessively elevated $(>33 \%$ to $<40 \%$ ). Best clinical management remains unclear. $\mathrm{DO}_{2}$ should be determined as a first step. Clinical assessment of physiology as it relates to the individual patient along with frequent reassessment of other clinical parameters would typically lead to a watchful waiting approach or more aggressive resuscitation. (Figure 8)

$\mathrm{O}_{2}$ extraction data helps assess the adequacy of $\mathrm{O}_{2}$ delivery. If adequate (extraction $<33 \%$ ) a vasopressor depending on the blood pressure or no further therapy is generally appropriate. Other possible interventions are shown in Figure 8, all titrated against a change in SVI/cardiac output and ultimately oxygen delivery.

In applying these algorithms at the bedside, the use of sound physiologic principles guides management in a group of patients in whom advanced hemodynamic monitoring can be easily and safely obtained (McGee, 2009).

\subsection{Total physiologic assessment for septic shock}

When possible but especially for those patients in whom we desire a more complete picture of cardiac performance typically those with normal or decreased stroke volume/cardiac output; echocardiography with assessment of biventricular function and ventricular interdependence along with pulmonary artery pressure allows for a complete description of cardiac performance and suggests possible therapies for augmentation if necessary. Inotropes for pure left ventricular failure or diagnosis and treatment of impairment of left ventricular filling from right ventricular distension as two common examples of how this additional cardiac functional anatomic data refines clinical care. Numerous other etiologies are possible and beyond the scope of this manuscript, but functional biventricular assessment is perhaps the final piece to a complete hemodynamic assessment of the critically ill septic shock patient. Flow $\left(\mathrm{SV} / \mathrm{CO}\right.$ and $\left.\mathrm{DO}_{2}\right)$, preload responsiveness (SVV/PPV), perfusion $\left(\mathrm{ScVO}_{2}\right.$ and calculation of $\mathrm{O}_{2}$ extraction) along with biventricular function (echo) can all be obtained reasonably safely for a majority of critically ill patients who routinely have arterial and central venous catheters and often have echocardiography performed.

Goal directed therapy saves lives of patients with severe sepsis. Application of physiology based volume management for the care of these patients further refines therapy while providing assurance that preload optimization is accomplished while minimizing the impact of excess volume. Titrated hemodynamic management using applied physiology has further potential to improve outcomes over more traditional approaches to the management of severe sepsis and septic shock.

\section{References}

Beaulieu Y. (2007) Bedside echocardiography in the assessment of the critically ill. Crit Care Med 35, No. 5 Suppl: S235 - S249.

Biais M, Vidil L, Sarrabay P et al: (2009) Changes in stroke volume induced by passive leg raising in spontaneously breathing patients: comparison between echocardiography and Vigileo/FloTrac device. Crit Care 13(6):R195. 
Bishop MH, Shoemaker WC, Appel PL et al: (1993) Relationship between supranormal circulatory values, time delays, and outcome in severely traumatized patients. Crit Care Med 21:56-63.

Bone R, Marik P, Sibbald WJ. (1993) Effect of stored-blood transfusion on oxygen delivery in patients with sepsis. JAMA 269(23):3024 - 3029.

Bouchard J, Soroko SB, Chertow GM, et al. (2009) Fluid accumulation, survival and recovery of kidney function in critically ill patients with acute kidney injury. Kidney International 76:422 - 427.

Boyd JH, Forbes J, Nakada T, et al. (2011) Fluid resuscitation in septic shock: A positive fluid balance and elevated central venous pressure are associated with increased mortality. Crit Care Med 39:259 - 265.

Cavallaro F, Sandroni C, Marano C et al: Diagnostic accuracy of passive leg raising for prediction of fluid responsiveness in adults: systematic review and meta-analysis of clinical studies. Intensive Care Med 2010, 36(9):1475-1483.

Court O, Kumar A, Parrillo JE, et al. (2002) Clinical Review : Myocardial depression in sepsis and septic shock. Critical Care 6:500 - 508.

Creamer JE, Edwards JD, Nightingale P: (1990) Hemodynamic and oxygen transport variables in cardiogenic shock secondary to acute myocardial infarction and response to treatment. Am J Cardiol 65:1297-1300.

Cryer HG, Richardson JD, Longmire-Cook S, et al: (1989) Oxygen delivery in patients with adult respiratory distress syndrome who undergo surgery. Correlation with multiple system organ failure. Arch Surg 124:1378-1384.

Danek SJ, Lynch JP, Wegg JG, et al. (1980) The dependence of oxygen uptake on oxygen delivery in the adult respiratory distress syndrome. Am Rev Respir Dis. 122: 387 $-395$.

DeBacker D, Heenen S, Piagnerelli M et al: (2005)Pulse pressure variations to predict fluid responsiveness: influence of tidal volume. Intensive Care Med 31(4):517523.

Dellinger RP, Levy M, Carlet JM, et al. (2008) Surviving Sepsis Campaign: International guidelines for management of severe sepsis and septic shock: 2008. Intensive Care Med 34:17 - 61 .

Edwards JD, Brown GCS, Nightingale P, et al: (1989) Use of survivors' cardiorespiratory values as therapeutic goals in septic shock. Crit Care Med 17:1098-1103.

Feissel M, Michard F, Mangin I, et al: (2001) Respiratory changes in aortic blood velocity as an indicator of fluid responsiveness in ventilated patients with septic shock. Chest 119(3):867-873.

Fernandes CJ, Akamine N, De Marco F, et al. (2001) Red blood cell transfusion does not increase oxygen consumption in critically ill septic patients. Critical Care 5:362 367.

Fernandes CJ, Akamine N, Knobel E. (2008) Myocardial depression in sepsis. Shock 30; Suppl 1:14-17.

Fuller BM, Gajera M, Schorr C, et al. (2010) The impact of packed red blood cell transfusion on clinical outcomes in patients with septic shock treated with early goal directed therapy. Indian J Crit Care Med 14(4):165 - 169. 
Gattinoni L, Brazzi L, Pelosi P, et al. (1995) A trial of goal-oriented hemodynamic therapy in critically ill patients. N Engl J Med 333:1025 - 1032.

Gilbert EM, Haupt MT, Mandanas RY et al: (1986) The effect of fluid loading, blood transfusion, and catecholamine infusion on oxygen delivery and consumption in patients with sepsis. Am Rev Respir Dis 134:873-878.

Griffee MJ, Merkel MJ, Wei KS. (2010) The role of echocardiography in hemodynamic assessment of septic shock. Crit Care Clin 26:365 - 382.

Hankein KB, Gronemeyer R, Held A et al: (1991) Use of continuous noninvasive measurement of oxygen consumption in patients with adult respiratory distress syndrome following shock of various etiologies. Crit Care Med 19:642649.

Hankein KB, Senker R, Schwarten JU et al: (1987) Evaluation of prognostic indices based on hemodynamic and oxygen transport variables in shock patients with adult respiratory distress syndrome. Crit Care Med 15:1-7.

Hayes MA, Timmins AC, Yau E, et al. (1994) Elevation of systemic oxygen delivery in the treatment of critically ill patients. N Engl J Med 330:1717 - 1722.

Hayes MA, Yau EHS, Timmins AC et al: (1993) Response of critically ill patients to treatment aimed at achieving supranormal oxygen delivery and consumption. Chest 103:886-895.

Hebert PC, Wells G, Blajchman MA, et al. (1999) A multicenter, randomized, controlled clinical trial of transfusion requirements in critical care. N Engl J Med 340:409 417.

Heyland DK, Cook DJ, King D, et al. (1996) Maximizing oxygen delivery in critically ill patients: A methodologic appraisal of the evidence. Crit Care Med 24(3): 517 524

IntelliVue M90: (2006) Networked patient monitors with portal technology for highest intensity care. Philips Medical Systems Brochure; Accessed on September 30, 2008, from www.medical.philips.com

Kasnitz P, Druger GL, Torra F, Simmons DH: (1976) Mixed venous oxygen tension and hyperlactatemia. Survival in severe cardiopulmonary disease. JAMA 236(6):570574.

Krafft P, Steltzer H, Hiesmayr M, et al. (1993) Mixed venous oxygen saturation in critically ill septic shock patients. The role of defined events. Chest 103:900 906)

Kumar A, Kumar A. (2009) Sepsis and Septic Shock. Chapter 57. Civetta, Taylor and Kirby's Critical Care, Fourth Edition. Lippincott, Williams and Wilkins 2009.

Ladakis C, Myrianthefs P, Karabinis A, et al. (2001) Central venous and mixed venous oxygen saturation in critically ill patients. Respiration 68(3):279 285

Lee J, Wright F, Barber R, Stanley L: (1972) Central venous oxygen saturation in shock: a study in man. Anesthesiology 36(5):472.

Magder S, Vanelli G. (1996) Circuit factors in the high cardiac output of sepsis. J Crit Care 11(4):155 - 166. 
Maitland K, Kiguli S, Opoka RO et al: (2011) Mortality after fluid bolus in African children with severe infection. New England J Med 364(26):2483-2495.

Marik PE, Baram M, Vahid B: (2008) Does trhe central venous pressure predict fluid responsiveness? A systemicatic review of the literature and the tale of severe mares. Chest 134(1):172-178.

Marik PE, Corwin HL. (2008) Efficacy of red blood cell transfusion in the critically ill: A systematic review of the literature. Crit Care Med 36:2667 - 2674.

McGee WT, Jodka P. (2002) Oxygen transport and tissue oxygenation. Chapter 3. Cardiopulmonary Critical Care BIOS Scientific Publishers, LTD. 2002.

McGee WT: (2009) A simple physiologic algorithm for managing hemodynamics using stroke volume and stroke volume variation: physiologic optimization program. J Inten Care Med;24(6):352-360.

Michard F, Boussat S, Chemla D et al: (2000) Relation between respiratory changes in arterial pulse pressure and fluid responsiveness in septic patients with acute circulatory failure. Am J Respir Crit Care Med 162(1):134-138.

Michard F, Richards G, Biais M et al: (2010) Using pulse pressure variation or stroke volume variation to diagnose right ventricular failure? Critical Care 14:451.

Michard F, Teboul JL: (2002) Predicting fluid responsiveness in ICU patients: a critical analysis of the evidence. Chest 121(6):2000-2008.

Monnet X, Rienzo M, Osman D et al: (2006) Passive leg raising predicts fluid responsiveness in the critically ill. Crit Care Med 34(5):1402-1407.

Murphy CV, Schramm GE, Doherty JA, et al. (2009) The importance of fluid management in acute lung injury secondary to septic shock. Chest 136:102 - 109.

Natanson C, Fink MP, Ballantyne HK, et al. (1986) Gram-negative bacteremia produces both severe systolic and diastolic cardiac dysfunction in a canine model that simulates human septic shock. J Clin Invest 78:259 - 270.

Nelson DP, Beyer C, Samsel RW, et al. (1987) Pathological supply dependence of $\mathrm{O}_{2}$ uptake during bacteremia in dogs. J Appl Physiol. 63: 1487 - 1492.

Nelson DP, Samsel RW, Wood LDH, et al. (1988) Pathological supply dependence of systemic and intestinal O2 uptake during endotoxemia. J Appl Physiol. 64: 2410 2419

Osman D, Ridel C, Ray P et al: (2007) Cardiac filling pressures are not appropriate to predict hemodynamic response to volume challenge. Crit Care Med 35(1): 64-68.

Parker MM, Shelhamer JH, Bacharach SL, et al. (1984) Profound but reversible myocardial depression in patients with septic shock. Ann of Intern Med 100:483 - 490.

Pathan N, Sandiford C, Harding SE, et al. (2002) Characterization of a myocardial depressant factor in meningococcal septicemia. Crit Care Med 30:2191 - 2198.

Payen D, Cornelie de Pont A, Sakr Y, et al. (2008) A positive fluid balance is associated with a worse outcome in patients with acute renal failure. Critical Care 12:R74

Perel A, Pizov R, Cotev S: (1987) Systolic blood pressure variation is a sensitive indicator of hypovolemia in ventilated dogs subjected to graded hemorrhage. Anesthesiology 67(4):498-502. 
Pieracci FM, Biffl WL, Moore EE. (2011) Current concepts in resuscitation. J Intensive Care Med published online 7 February 2011

Reinhart K: (1989) Monitoring $\mathrm{O}_{2}$ transport and tissue oxygenation in critically ill patients. In: Reinhart K, Eyrich K eds. Clinical Aspects of O2 Transport and Tissue Oxygenation. Berlin, Germany: Springer; 195-211.

Reinhart K, Kuhn HU, Hartog C, Bredle DL: (2004) Continuous central venous and pulmonary artery oxygen saturation monitoring in the critically ill. Intensive Care Med 30(8):1572-1578.

Rivers EP, Coba V, Visbal A, et al. (2008) Management of Sepsis: Early resuscitation. Clin Chest Med $689-704$.

Rivers EP, Kruse JA, Jacobsen G, et al. (2007) The influence of early hemodynamic optimization on biomarker patterns of severe sepsis and septic shock. Crit Care Med 35(9):2016 - 2024

Rivers E, Nguyen B, Havstad S, et al.(2001) Early goal-directed therapy in the treatment of severe sepsis and septic shock. N Engl J Med 345:1368 - 77.

Ronco JJ, Fenwick JC, Tweeddale MG, et al. (1993) Identification of the critical oxygen delivery for anaerobic metabolism in critically ill septic and non-septic humans. JAMA 270(14): 1724 - 1730.

Sakr Y, Chierego M, Piagnerelli M, et al. (2007) Microvascular response to red blood cell transfusion in patients with severe sepsis. Crit Care Med 35:1639 - 1644.

Shibutani k, Komatsu T, Kubal K, et al. (1983) Critical level of oxygen delivery in man. Crit Care Med. 11:640 - 643

Shoemaker WC, Appel PL, Kram HB: (1993) Hemodynamic and oxygen transport responses in survivors and non-survivors of high-risk surgery. Crit Care Med 21:977-1097.

Shoemaker WC, Appel PL, Kram HB et al: (1993) Temporal hemodynamic and oxygen patterns in medical patients. Chest 104:1529-1536.

Shoemaker WC, Appel PL, Kram HB et al: (1993) Sequence of physiologic patterns in surgical septic shock. Crit Care Med 21:1876-1889.

Simmons DH, Alpas AP, Tashkin DP, Coulson A: (1978) Hyperlactatemia due to arterial hypoxemia or reduced cardiac output, or both. Am Phys Soc 45(2):195.

Shoemaker WC, Appel PL, Kram HB, et al. (1988) Prospective trial of supranormal values of survivors as therapeutic goals in high risk surgical patients. Chest 94:1176 1186.

Tavernier B, Makhotine O, Lebuffe G et al: (1998) Systolic pressure variation as a guide to fluid therapy in patients with sepsis-induced hypotension. Anesthesiology 89(6):1313-1321.

Teule Gjj, Van Lingen A, Verweij-van Vught MA, et al. (1984) Role of peripheral pooling in porcine Escherichia coli sepsis. Circ Shock 12:115 - 123.

The National Heart, Lung and Blood Institute Acute Respiratory Distress Syndrome (ARDS) Clinical Trials Network. (2006) Comparison of two fluid-management strategies in acute lung injury. N Engl J Med 354:2564 - 2575. 
Von Ballmoos MW, Takala J, Roeck M et al: (2010) Pulse-pressure variation and hemodynamic response in patients with elevated pulmonary artery pressure: a clinical study. Critical Care 14:R111. 


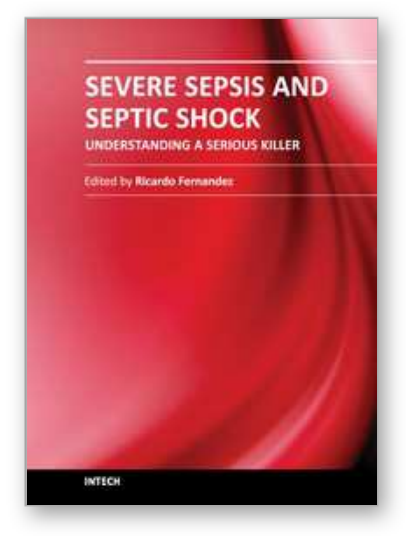

\author{
Severe Sepsis and Septic Shock - Understanding a Serious Killer \\ Edited by Dr Ricardo Fernandez
}

ISBN 978-953-307-950-9

Hard cover, 436 pages

Publisher InTech

Published online 10, February, 2012

Published in print edition February, 2012

Despite recent advances in the management of severe sepsis and septic shock, this condition continues to be the leading cause of death worldwide. Some experts usually consider sepsis as one of the most challenging syndromes because of its multiple presentations and the variety of its complications. Various investigators from all over the world got their chance in this book to provide important information regarding this deadly disease . We hope that the efforts of these investigators will result in a useful way to continue with intense work and interest for the care of our patients.

\title{
How to reference
}

In order to correctly reference this scholarly work, feel free to copy and paste the following:

William McGee and Patrick Mailloux (2012). Applied Physiology and the Hemodynamic Management of Septic Shock Utilizing the Physiologic Optimization Program, Severe Sepsis and Septic Shock - Understanding a Serious Killer, Dr Ricardo Fernandez (Ed.), ISBN: 978-953-307-950-9, InTech, Available from:

http://www.intechopen.com/books/severe-sepsis-and-septic-shock-understanding-a-serious-killer/appliedphysiology-and-the-hemodynamic-management-of-septic-shock-utilizing-the-physiologic-optimiza

\section{INTECH}

open science | open minds

\section{InTech Europe}

University Campus STeP Ri

Slavka Krautzeka 83/A

51000 Rijeka, Croatia

Phone: +385 (51) 770447

Fax: +385 (51) 686166

www.intechopen.com

\section{InTech China}

Unit 405, Office Block, Hotel Equatorial Shanghai

No.65, Yan An Road (West), Shanghai, 200040, China

中国上海市延安西路65号上海国际贵都大饭店办公楼405单元

Phone: +86-21-62489820

Fax: +86-21-62489821 
(C) 2012 The Author(s). Licensee IntechOpen. This is an open access article distributed under the terms of the Creative Commons Attribution 3.0 License, which permits unrestricted use, distribution, and reproduction in any medium, provided the original work is properly cited. 